\title{
Mutual information density of stochastic integrate-and-fire models
}

\author{
Davide Bernardi ${ }^{1,2^{*}}$, Benjamin Lindner ${ }^{1,3}$ \\ From Twenty Second Annual Computational Neuroscience Meeting: CNS*2013 \\ Paris, France. 13-18 July 2013
}

The coherence function of integrate-and-fire neurons shows low-pass properties in the most diverse firing regimes [1]. While the coherence function provides a good approximation to the full information transfer properties in the case of a weak input, for a strong input non-linear encoding could play an important role. The complete information transfer is quantified by Shannon's mutual information rate [2] which has been estimated in certain biological model systems [3]. In general, the exact analytical calculation of the mutual information rate is unfeasible and even the numerical estimation is demanding [4].

Numerical calculation of the mutual information rate is now a commonly adopted practice, but it does not indicate what aspects of the stimulus are best represented by the neuronal response. We developed a numerical procedure to directly calculate a frequencyselective version of the mutual information rate. This can be used to study how different frequency components of a Gaussian stimulus are encoded in neural models without invoking a weak-signal paradigm.

\section{Acknowledgements}

This work was funded by the BMBF (FKZ: 01GQ1001A).

\section{Author details \\ ${ }^{1}$ Bernstein Center for Computational Neuroscience, Berlin 10115, Germany. ${ }^{2}$ Department of Physics, Freie Universität Berlin, Berlin, Berlin 14195, Germany. ${ }^{3}$ Department of Physics, Humboldt-Universität zu Berlin, Berlin,} Berlin 12489, Germany.

Published: 8 July 2013

\section{References}

1. Vilela RD, Lindner B: A comparative study of different integrate fire neurons: spontaneous activity, dynamical response, and stimulusinduced correlation. Phys Rev E 2009, 80:031909.

\footnotetext{
* Correspondence: dbernard@zedat.fu-berlin.de
}

1 Bernstein Center for Computational Neuroscience, Berlin 10115, Germany Full list of author information is available at the end of the article
2. Shannon C: A Mathematical Theory of Communication. The Bell System Technical Journal 1948, 27:379-423, 623-656.

3. Strong SP, Koberle R, de Ruyter van Steveninck R, Bialek W: Entropy and Information in Neural Spike Trains. Phys Rev Lett 1998, 80(1):197-200.

4. Panzeri S, Senatore R, Montemurro MA, Petersen RS: Correcting for the sampling bias problem in spike train information measures. $J$ Neurophysiol 2007, 98(3):1064-1072.

doi:10.1186/1471-2202-14-S1-P245

Cite this article as: Bernardi and Lindner: Mutual information density of stochastic integrate-and-fire models. BMC Neuroscience 2013 14(Suppl 1): P245.
Submit your next manuscript to BioMed Central and take full advantage of:

- Convenient online submission

- Thorough peer review

- No space constraints or color figure charges

- Immediate publication on acceptance

- Inclusion in PubMed, CAS, Scopus and Google Scholar

- Research which is freely available for redistribution

\section{() Biomed Central}

C Biomed Central

(c) 2013 Bernardi and Lindner; licensee BioMed Central Ltd. This is an Open Access article distributed under the terms of the Creative Commons Attribution License (http://creativecommons.org/licenses/by/2.0), which permits unrestricted use, distribution, and reproduction in any medium, provided the original work is properly cited. 